\title{
Analysis of mitochondrial DNA using amplified fragment length polymorphism markers of isonuclear allocytoplasmic male sterile wheat accessions and their maintainer lines
}

\author{
M. Ejaz*, Z. Qidi*, Z. Gaisheng, W. Qunzhu and Z. Xinbo \\ College of Agronomy, Northwest A\&F University, Yangling, Shaanxi, China \\ *These authors contributed equally to this study. \\ Corresponding author: Z. Gaisheng \\ E-mail: zhanggsh@public.xa.sn.cn
}

Genet. Mol. Res. 12 (4): 5207-5214 (2013)

Received February 27, 2013

Accepted August 19, 2013

Published October 23, 2013

DOI http://dx.doi.org/10.4238/2013.October.30.5

\begin{abstract}
To produce a good F1 hybrid variety wheat crop, it is necessary to explore novel cytoplasmic male sterility (CMS) lines and their maintainer line. This study aimed to identify cytoplasmic variation in three isonuclear-alloplasmic male sterile lines Aegilops kotschyi (Ae. kots) -90-110, Aegilops ventricosa (Ae.ven) -90-110, and Triticum spelta (T.spelta) -90-110 and their maintainer line, A-90-110, at the molecular level. Mitochondrial DNA (mtDNA) was isolated using a combination of centrifugation and density gradient ultracentrifugation, sucrose sedimentation, lysis with sodium dodecyl sulfate (SDS), potassium proteinase, and phenol/chloroform extraction methods. To detect mtDNA purity, specific primers were designed for nuclear ( $\beta$-actin) and mitochondrial (COXIII) genes. Results indicated that the mtDNA was pure, and therefore suitable for polymerase chain reaction (PCR) and genetic analysis. Comparative analysis of mtDNA was conducted using amplified fragment length polymorphism (AFLP) markers. Reproducible polymorphisms were detected between the Aegilops and Triticum species and the male sterile lines. Four specific primers were screened from 64
\end{abstract}


AFLP marker primers, which provided the molecular basis for further studies investigating specific cytoplasmic male sterility characteristics.

Key words: Wheat; Cytoplasmic male sterility; mtDNA; AFLP; Molecular marker

\section{INTRODUCTION}

Wheat (Triticum aestivum L.) is a staple food and one of the most important agricultural crops in the world. Wheat constitutes the basis for human nutrition and is of enormous economic importance worldwide. Wheat is used mainly for human consumption and supports nearly $35 \%$ of the world's population (Schuster et al., 2009). Cytoplasmic male sterility (CMS) is a very important trait for improving yield and quality of crops to meet the needs of increasing global population. In some well-studied species, the trait appears to be associated with mitochondrial DNA (mtDNA) mutations that disrupt mitochondrial function at a critical stage of anther development, thus causing male sterility (Breiman and Galun, 1990; Hanson, 1991; Mackenzie et al., 1994). Molecular studies involving sterile and fertile plants have revealed variations in the restriction pattern of mtDNA transcripts and demonstrated differences at the molecular level (Levings and Pring, 1976; Song and Hedgcoth, 1994). Alterations in specific mitochondrial genes and inserts have been identified (Song and Hedgcoth, 1994). Moreover, nuclear and cytoplasmic combinations from different plant species often leads to CMS, indicating that sterility is likely caused by functional incompatibilities between the nuclear and mitochondrial genomes (Kofer et al., 1991). The contribution of mtDNA to the expression of CMS has been demonstrated in a variety of plant species (Braun et al., 1992). Extensive rearrangements in mitochondrial genomes between CMS and fertile males are considered as a general source of CMS (Braun et al., 1992; Mackenzie et al., 1994). It is generally believed that plant CMS results from mtDNA rearrangements, such as insertions and deletions generated by mutations. These mutations can express the open reading frame, leading to changes in transcription and translation of the product, which ultimately result in male plant sterility (Lorenz et al., 1997; Budar et al., 2003; McDermott et al., 2008; Chen et al., 2009; Han et al., 2010). CMS of the wheat mitochondrial atp6 gene transcript editing sites edit inadequate transcripts, which affect the normal functioning of mitochondria, thereby affecting the generation of receptor male sterility (Li et al., 2007). Wheat mitochondrial genome variability is likely related to changes in the nature of the sterile line; however, it is difficult to determine whether the sterility is due to nuclear genes, cytoplasmic genes, or interactions between nuclear and cytoplasmic elements. To solve this problem, in this study, continuous backcrossing was performed in up to a dozen generations in order to establish nuclear male sterile wheat lines with the same nuclear genetic background. These lines are considered to have the same nuclear genome and different cytoplasmic genomes. Amplified fragment length polymorphisms (AFLP) markers were used to analyze wheat mtDNA at the molecular level in order to identify the different types of sterile cytoplasm variations, as well as to determine specific fertility. Together, these results should help to improve the performance and actual utilization of cytoplasmic infertility (Vos et al., 1995).

\section{MATERIAL AND METHODS}

Four wheat accessions, Aegilops kotschyi, Aegilops ventricosa, Triticum spelta, and one 
fertile common wheat variety, 90-110, were used in the present investigation. These lines were derived from recurrent backcrosses of Aegilops kotschyi-Chris, Aegilops ventricosa-Chris, and Triticum spelta-Chris. Yellow etiolated wheat seedlings were grown in the dark over a period of 7 to 10 days at $30^{\circ} \mathrm{C}$ in growth chambers, and their growth needs were met by nutrients supplied by sterile water only. The plants were strictly protected from light. All of the cultural procedures were performed in the dark to prevent plants from becoming green, and to obtain high quality mtDNA free of any chloroplast, genomic DNA, or other impurities. This study was carried out with emphasis on mtDNA variation among Aegilops to identify the different types of sterile cytoplasm as well as specific fertility in order to improve the performance of the actual utilization of cytoplasmic infertility and to produce a good hybrid variety at the Key Laboratory of Crop Heterosis of Shaanxi Province, Northwest Agricultural \& Forest University, Yangling, China.

\section{DNA isolation}

mtDNA was isolated from etiolated shoots as described by Li et al. (2007). mtDNA was isolated with differential centrifugation, DNase treatment, lysis with sodium dodecyl sulfate (SDS), and potassium proteinase, removing proteins by TE-saturated phenol/chloroform extraction, and a final RNase treatment (Figure 1). The mtDNA samples were tested for purity using spectrophotometry and agarose gel electrophoresis. We analyzed the samples through amplification of the nuclear $\beta$ subunit, that is, $\beta$-actin genes, and the mitochondrial Coxidase subunit (COXIII) gene. Results demonstrated that the mtDNA was not contaminated by nuclear DNA, plastid DNA, RNA, or protein, and could successfully be used for polymerase chain reaction (PCR), cloning, and Southern blot analyses.

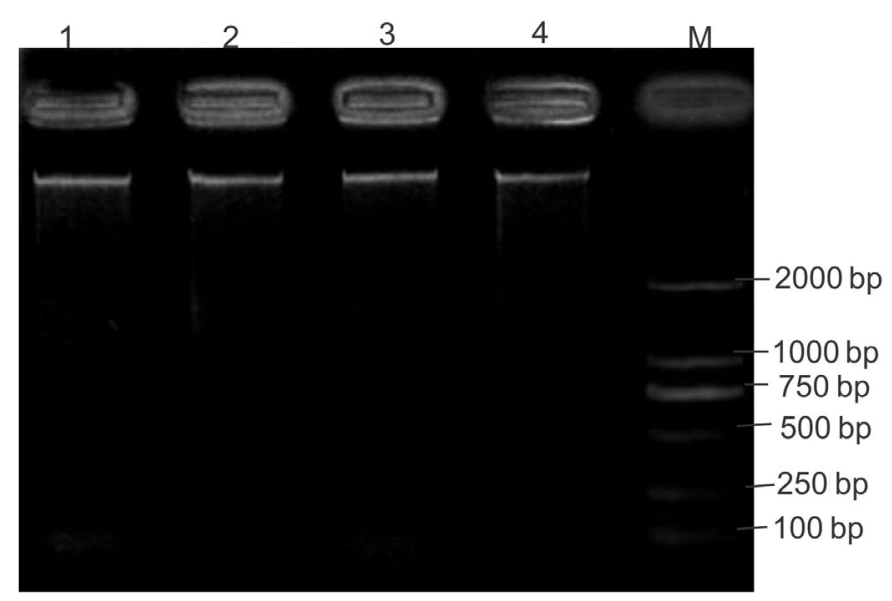

Figure 1. Results of mtDNA. Lane $1=(\mathrm{A})-90-110$; lane $2=\mathrm{ms}($ Kots)-90-110; lane $3=\mathrm{ms}($ Ven)-90-110; lane $4=$ $\mathrm{ms}(\mathrm{S})-90-110$. Lane $M=$ marker DL 2000.

\section{AFLP analysis}

AFLP analysis was performed using commercially available kits following manufacturer instructions (Fermentas). Sixty-four primer combinations (Table 1) were tested for poly- 
morphism analysis between the varieties. Two hundred fifty nano grams mtDNA was restricted with $5 \mathrm{U}$ each of EcoRI and MseI enzymes for $180 \mathrm{~min}$ at $37^{\circ} \mathrm{C}$ and for $150 \mathrm{~min}$ at $65^{\circ} \mathrm{C}$, respectively, in $20 \mu \mathrm{L}$ reaction volumes, and the enzymes were heat-inactivated by incubating tubes at $70^{\circ} \mathrm{C}$ for $15 \mathrm{~min}$. The DNA fragments were ligated to appropriate adapters using $1 \mathrm{U} \mathrm{T}_{4}$ DNA ligase with $1 \mu \mathrm{L} \mathrm{EcoRI} \mathrm{and} \mathrm{MseI} \mathrm{(primer} \mathrm{sequences} \mathrm{for} \mathrm{EAF,} \mathrm{EAR,} \mathrm{MAF,} \mathrm{and} \mathrm{MAR} \mathrm{are}$ listed in Table 2, which were prepared according to manufacturer instructions) adapter ligation mixture by incubating at $16^{\circ} \mathrm{C}$ for $12 \mathrm{~h}$ in $20 \mu \mathrm{L}$ reaction volumes. The ligated DNA mixture was pre-amplified using adapter primers with EcoRI (E00) and MseI (M00) selective nucleotides (Table 2), $1.6 \mu \mathrm{L} 2.25 \mathrm{mM}$ dNTPs, $0.1 \mu \mathrm{L} 5 \mathrm{U} / \mu \mathrm{L}$ rTaq, and $2 \mu \mathrm{L}$ PCR buffer in a final volume of $20 \mu \mathrm{L}$. The PCR cycling parameters were as follows: 1 cycle of $94^{\circ} \mathrm{C}$ for $30 \mathrm{~s} ; 32$ cycles each of $94^{\circ} \mathrm{C}$ for $30 \mathrm{~s}, 56^{\circ} \mathrm{C}$ for $45 \mathrm{~s}, 72^{\circ} \mathrm{C}$ for $120 \mathrm{~s}$; and one cycle of $72^{\circ} \mathrm{C}$ for $10 \mathrm{~min}$. For selective amplification, $1 \mu \mathrm{L}$ each EcoRI and MseI primers were mixed with $5 \mu \mathrm{L} 30$-fold diluted preamplifier DNA, $1.6 \mu \mathrm{L}$ dNTPs, $0.2 \mu \mathrm{L}$ rTaq, and $2 \mu \mathrm{L}$ PCR buffer in a final volume of $20 \mu \mathrm{L}$. The following PCR cycling parameters were used for selective amplification: the $1 \mathrm{st}$ cycle was at $94^{\circ} \mathrm{C}$ for $60 \mathrm{~s}$ and the $2 \mathrm{nd}$ cycle was at $94^{\circ} \mathrm{C}$ for $30 \mathrm{~s}, 60^{\circ} \mathrm{C}$ for $45 \mathrm{~s}$, and $72^{\circ} \mathrm{C}$ for $60 \mathrm{~s}$. During the next 15 cycles, the annealing temperature was lowered by $1^{\circ} \mathrm{C}$ per cycle. The temperature conditions for the next 25 cycles were $94^{\circ} \mathrm{C}$ for $30 \mathrm{~s}, 45^{\circ} \mathrm{C}$ for $45 \mathrm{~s}$, and $72^{\circ} \mathrm{C}$ for $60 \mathrm{~s}$. The amplified products were analyzed on a $6 \%$ denaturing polyacrylamide gel.

\begin{tabular}{|c|c|c|c|c|c|c|c|}
\hline E1/M1 & $\mathrm{E} 1 / \mathrm{M} 2$ & E1/M3 & E1/M4 & E1/M5 & E1/M6 & E1/M7 & E1/M8 \\
\hline $\mathrm{E} 2 / \mathrm{M} 1$ & $\mathrm{E} 2 / \mathrm{M} 2$ & $\mathrm{E} 2 / \mathrm{M} 3$ & E2/M4 & E2/M5 & E2/M6 & E2/M7 & E2/M8 \\
\hline $\mathrm{E} 3 / \mathrm{M} 1$ & $\mathrm{E} 3 / \mathrm{M} 2$ & E3/M3 & E3/M4 & E3/M5 & E3/M6 & $\mathrm{E} 3 / \mathrm{M} 7$ & E3/M8 \\
\hline E4/M1 & $\mathrm{E} 4 / \mathrm{M} 2$ & $\mathrm{E} 4 / \mathrm{M} 3$ & E4/M4 & E4/M5 & E4/M6 & $\mathrm{E} 4 / \mathrm{M} 7$ & E4/M8 \\
\hline $\mathrm{E} 5 / \mathrm{M} 1$ & $\mathrm{E} 5 / \mathrm{M} 2$ & $\mathrm{E} 5 / \mathrm{M} 3$ & E5/M4 & E5/M5 & E5/M6 & $\mathrm{E} 5 / \mathrm{M} 7$ & E5/M8 \\
\hline $\mathrm{E} 6 / \mathrm{M} 1$ & E6/M2 & E6/M3 & E6/M4 & E6/M5 & E6/M6 & E6/M7 & E6/M8 \\
\hline E7/M1 & $\mathrm{E} 7 / \mathrm{M} 2$ & E7/M3 & E7/M4 & E7/M5 & E7/M6 & E7/M7 & E7/M8 \\
\hline $\mathrm{E} 8 / \mathrm{M} 1$ & $\mathrm{E} 8 / \mathrm{M} 2$ & E8/M3 & E8/M4 & E8/M5 & E8/M6 & E8/M7 & E8/M8 \\
\hline
\end{tabular}

\begin{tabular}{|c|c|}
\hline Code & Primer sequence \\
\hline EAF & 5'-GTA GAC TGC GTA CC-3' \\
\hline EAR & 5'-AAT TGG TAC GCA GTC TAC-3' \\
\hline MAF & 5'-GAC GAT GAG TCC TGA G-3' \\
\hline MAR & 5'-TAC TCA GGA CTC AT-3' \\
\hline E00 (Pre-amplifier primer) & 5'-GTA GAC TGC GTA CCA ATTC A-3' \\
\hline M00 (Pre-amplifier primer) & 5'-GAC GAT GAG TCC TGA GTAA C-3' \\
\hline E1 & 5'-GTA GAC TGC GTA CCA ATTC AAC-3' \\
\hline E2 & 5'-GTA GAC TGC GTA CCA ATTC AAG-3' \\
\hline E3 & 5'-GTA GAC TGC GTA CCA ATTC ACA-3' \\
\hline E4 & 5'-GTA GAC TGC GTA CCA ATTC ACT-3' \\
\hline E5 & 5'-GTA GAC TGC GTA CCA ATTC ACC-3' \\
\hline E6 & 5'-GTA GAC TGC GTA CCA ATTC ACG-3' \\
\hline E7 & 5'-GTA GAC TGC GTA CCA ATTC AGC-3' \\
\hline E8 & 5'-GTA GAC TGC GTA CCA ATTC AGG-3' \\
\hline M1 & 5'-GAC GAT GAG TCC TGA GTAA CAA-3' \\
\hline M2 & 5'-GAC GAT GAG TCC TGA GTAA CAC-3' \\
\hline M3 & 5'-GAC GAT GAG TCC TGA GTAA CAG-3' \\
\hline M4 & 5'-GAC GAT GAG TCC TGA GTAA CAT-3' \\
\hline M5 & 5'-GAC GAT GAG TCC TGA GTAA CTA-3' \\
\hline M6 & 5'-GAC GAT GAG TCC TGA GTAA CTC-3' \\
\hline M7 & 5'-GAC GAT GAG TCC TGA GTAA CTG-3' \\
\hline M8 & 5'-GAC GAT GAG TCC TGA GTAA CTT-3' \\
\hline
\end{tabular}




\section{mtDNA purity identification}

We analyzed the samples through the amplification of the nuclear $\beta$ subunit, that is, $\beta$-actin genes, and the mitochondrial Coxidase subunit (COXIII) gene. This entailed the use of two separate $20 \mu \mathrm{L}$ volumes containing $1 \mu \mathrm{L}$ mtDNA, $6 \mu \mathrm{LddH}_{2} \mathrm{O}, 1 \mu \mathrm{L}$ forward and reverse gene-specific primers, and $10 \mu \mathrm{L}$ master mix. The PCR conditions were as follows: $5 \mathrm{~min}$ at $94^{\circ} \mathrm{C} ; 5$ cycles each of $1 \mathrm{~min}$ at $94^{\circ} \mathrm{C}, 30 \mathrm{~s}$ at $60^{\circ} \mathrm{C}$, and $1 \mathrm{~min}$ at $70^{\circ} \mathrm{C}$; and 35 cycles each of $50 \mathrm{~s}$ at $94^{\circ} \mathrm{C}, 1 \mathrm{~min}$ at $60^{\circ} \mathrm{C}, 50 \mathrm{~s}$ at $72^{\circ} \mathrm{C}$, and $6 \mathrm{~min}$ at $72^{\circ} \mathrm{C}$. The products were separated on $1 \%(\mathrm{w} / \mathrm{v})$ agarose gel by electrophoresis. The 400 -bp mitochondrial COXIII gene was amplified and the $\beta$-actin gene was not amplified, which demonstrated that the mtDNA was not contaminated by nuclear DNA, plastid DNA, RNA or protein, and could be successfully used for PCR, cloning, and Southern blot analyses (Figure 2).

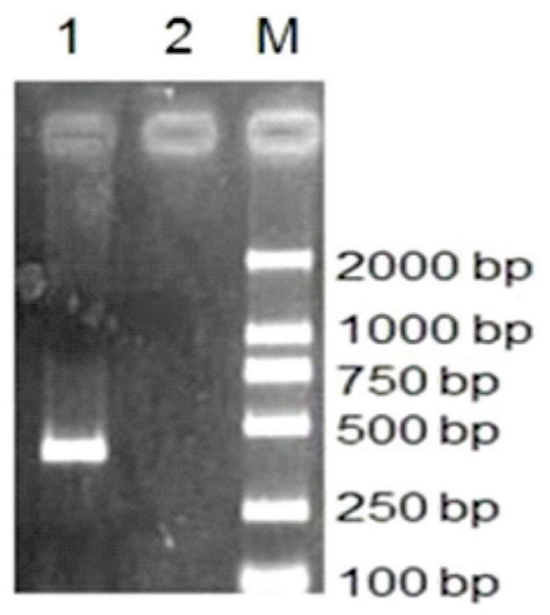

Figure 2. Lane 1 = COXIII; lane $2=\beta$-actin; lane $M=$ marker DL 2000 .

\section{RESULTS}

For AFLP analyses, all 64 primer pairs (Table 1) were used to examine polymorphisms between the three alloplasmic nuclear male sterile lines and their maintainer line of wheat crop. mtDNA of these lines was digested with the EcoRI and MseI enzymes. Dozens of clear bright bands were obtained by polyacrylamide gel electrophoresis. From the 64 primer pairs, four primer combinations were screened out (E1/M7, E4/M2, E6/M4, and E7/M6) that showed better polymorphism among these lines (Figures 3 and 4). Primer E1/M7 amplified three specific bands of approximately 200, 400, and $750 \mathrm{bp}$ in the A. kotschyi CMS line (Ae. kots-90-110), while the T. spelta sterile line (T.spelta-90-110) amplified a 500 bp specific band, which could be associated with $A$. kotschyi and $T$. spelta cytoplasmic infertility (Figure 3 ). The primer pair E4/M2 amplified a 200 bp specific band in the Ae.kots-90-110 sterile line, where as it amplified two specific bands of approximately 1000 and $600 \mathrm{bp}$ in the $A$. ventricosa sterile line (Ae.ven-90-110) (Figure 3). The primer E6/M4 amplified a fragment of approximately 200 bp and a specific gene of $250 \mathrm{bp}$ in the Ae.kots-90-110 sterile line (Figure 4). The primer pair 
E7/M6 amplified two fragments of approximately 300 and 400 bp in T.spelta-90-110, which represented the genes responsible for infertility (Figure 4). From these results, mitochondrial male sterility could be identified in the CMS lines.

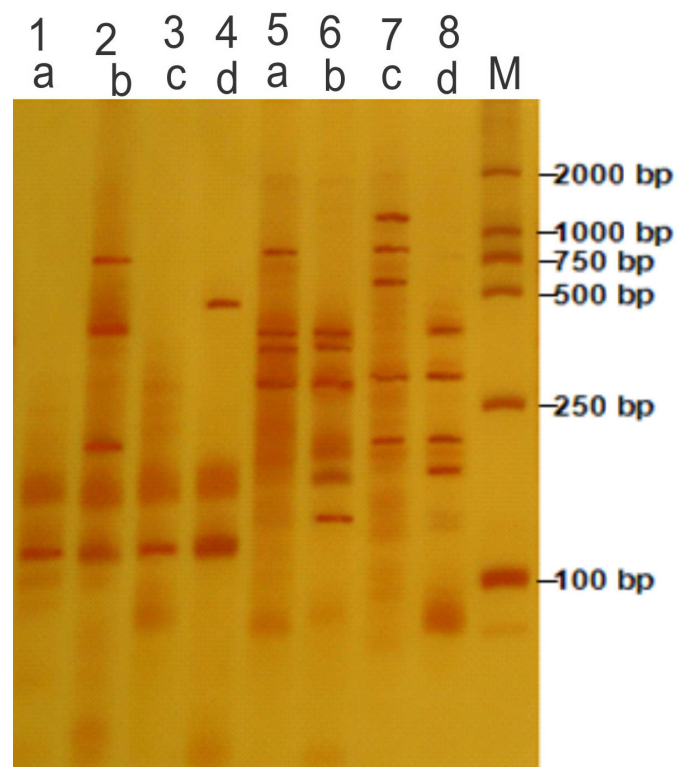

Figure 3. AFLP amplification profiles of three CMS lines and maintainer line. Primer E1/M7: lane 1a=(A)-90-110; lane $2 b=\mathrm{ms}(\mathrm{Kots})-90-110$; lane $3 c=\mathrm{ms}(\mathrm{Ven})-90-110$; lane $4 d=\mathrm{ms}(\mathrm{S})-90-110$. Primer E4/M2: lane $5 a=(\mathrm{A})-90$ 110; lane $6 b=\mathrm{ms}($ Kots)-90-110; lane $7 c=\mathrm{ms}($ Ven)-90-110; lane $8 d=\operatorname{ms}(\mathrm{S})-90-110$; lane $M=$ marker DL 2000.

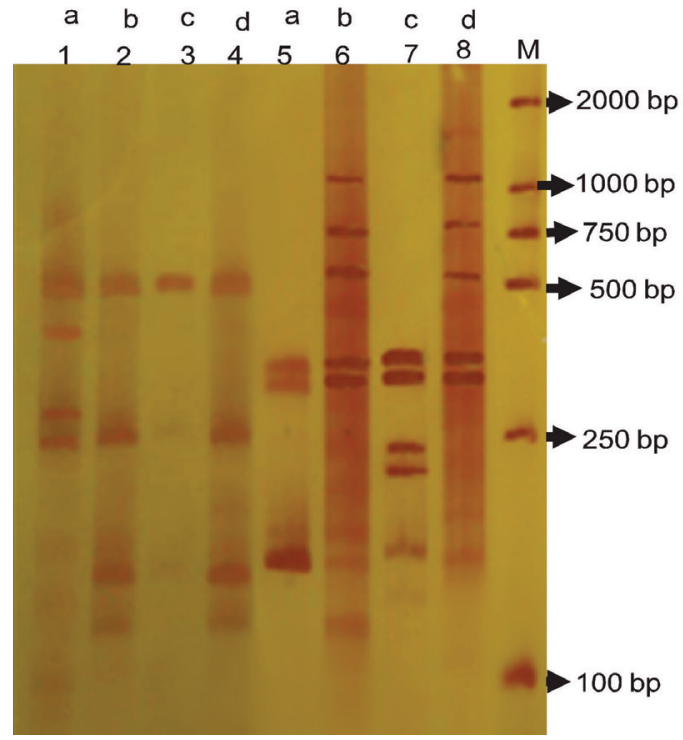

Figure 4. AFLP amplification profiles of three CMS lines and maintainer line. Primer E7/M6: lane $1 a=\mathrm{ms}(\mathrm{S})-90$ 110; lane $2 b=\mathrm{ms}($ Ven)-90-110; lane $3 c=\mathrm{ms}($ Kots)-90-110; lane $4 d=(\mathrm{A})-90-110$. Primer E6/M4: lane 5a $=\mathrm{ms}(\mathrm{S})-$ 90-110; lane $6 b=\mathrm{ms}($ Ven)-90-110; lane 7c = ms(Kots)-90-110; lane 8d=(A)-90-110; lane $M=$ marker DL 2000. 


\section{DISCUSSION}

Mitochondria contain genes that cause male sterility. Inter- or intramolecular rearrangements at specific sites of the mitochondrial genome result in CMS in plants (Dewey et al., 1986). Using molecular marker technology, differences in specific sites related to CMS were identified in the mitochondrial genome of male sterile lines compared with their maintainer line. Previously, wheat genetic diversity was compared with a rapid amplified polymorphic DNA (RAPD) molecular marker (Gao et al., 2011); however, this marker was not efficient due to its poor reproducibility.

AFLP molecular markers show good reproducibility, stability, and heterogeneity, and results are therefore more reliable. This study was based on three nuclear male sterile lines of wheat crop and their maintainer line. Four pairs of primers were screened out, which showed clear differences between the nuclear male sterile lines and the maintainer fertile line. These stable differences will prove to be helpful for assessing CMS in K, Ven, and S-type wheat crops. Under normal circumstances, male sterility and fertility restoration are caused by cytoplasmic genes ( $\mathrm{Li}$ et al., 1998). However, it is generally very difficult to assess whether this phenomenon is due to nuclear or cytoplasmic elements. The three lines used in the present study were developed after back crossing of a male sterile line of the homo-nucleus for up to 15 generations. The results showed that these differences were due to the cytoplasm. The cloning, sequencing, and expression of these specific fragments will provide a foundation for more in depth investigations and further discovery and excavation of new wheat CMS-related genes.

Mitochondria was isolated with differential centrifugation, DNaseI enzyme treatment, lysis with SDS, and potassium proteinase, removing proteins by TE-saturated phenol/chloroform extraction and a final RNase enzyme treatment for obtaining pure and good quality mtDNA that was suitable for PCR and genetic analysis. Cytoplasmic variations were identified in three isonuclear, alloplasmic male sterile lines, Ae.kots-90-110, Ae.ven-90-110, and T.spelta-90-110, and their maintainer line, A-90-110, at the molecular level. AFLP analysis revealed stable polymorphisms; four pair of primers were screened out to detect the different fragments responsible for CMS in these lines, which will provide a foundation for further study.

\section{ACKNOWLEDGMENTS}

Research supported by the National High Technology Research and Development Program of China (\#2011AA10A106), the National Natural Science Foundation of China (\#31071477, \#31371697), and the Key Scientific and Technological Innovation Special Projects of Shaanxi Province “13115” (\#2010ZDKG-68).

\section{REFERENCES}

Braun CJ, Braun GG and Levings III CS (1992). Cytoplasmic Male Sterility. In: Cell Organelles: Plant Gene Research (Herrmann RG, ed.). Springer-Verlag, Wien-New York, 219-245.

Breiman A and Galun E (1990). Nuclear-mitochondrial interrelation in angiosperms. Plant Sci. 71: 3-19.

Budar F, Touzet P and De Paepe R (2003). The nucleo-mitochondrial conflict in cytoplasmic male sterilities revisited. Genetica 117: 3-16.

Chen RH, Ye JX, Zhang GS, Wang JS et al. (2009). Differential proteomic analysis of anther proteins between cytoplasmicnuclear male sterility line and its maintainer in wheat (Triticum aestivum L.). Progr. Biochem. Biophys 36: 431-440.

Dewey RE, Levings CS 3rd and Timothy DH (1986). Novel recombinations in the maize mitochondrial genome produce 
a unique transcriptional unit in the Texas male-sterile cytoplasm. Cell 44: 439-449.

Gao CB, Zhang GS and Lan HY (2011). Polymorphism detection and analysis of mtDNA from iso-nuclear and allocytoplasm of wheat male sterile lines by RAPD. J. Triticeae Crop 31: 21-24.

Han YF, Zhang LY, Hu JM, Zhang GS et al. (2010). Editing sites in transcript of mitochondrial atp6 gene of male sterile line with Aegilops kotschyi cytoplasm in wheat. Acta Agron. Sin. 36: 2179-2184.

Hanson MR (1991). Plant mitochondrial mutations and male sterility. Annu. Rev. Genet. 25: 461-486.

Kofer W, Glimelius K and Bonnett HT (1991). Modifications of mitochondrial DNA cause changes in floral development in homeotic-like mutants of tobacco. Plant Cell 3: 759-769.

Levings CS 3rd and Pring DR (1976). Restriction endonuclease analysis of mitochondrial DNA from normal and Texas cytoplasmic male-sterile maize. Science 193: 158-160.

Li CY and Wang B (1998). Mitochondrial DNAs of cytoplsamic male sterile lines of K- and V-type in wheat. Acta Phytophysiol. Sinica 24: 153-158.

Li WQ, Zhang GS, Wang K, Niu N, et al. (2007). An efficient method for isolation of mitochondrial DNA in wheat. $Y i$ Chuan 29: 771-775.

Lorenz M, Weihe A and Borner T (1997). Cloning and sequencing of RAPD fragments amplified from mitochondrial DNA of male-sterile and male-fertile cytoplasm of sugar beet (Beta vulgaris L.). Theor. Appl. Genet. 94: 273-278.

Mackenzie S, He S and Lyznik A (1994). The elusive plant mitochondrion as a genetic system. Plant Physiol. 105: 775780.

McDermott P, Connolly V and Kavanagh TA (2008). The mitochondrial genome of a cytoplasmic male sterile line of perennial ryegrass (Lolium perenne L.) contains an integrated linear plasmid-like element. Theor. Appl. Genet. 117: 459-470.

Schuster I, Vieira ES, da Silva GJ, de Assis FF, et al. (2009). Genetic variability in Brazilian wheat cultivars assessed by microsatellite markers. Genet. Mol. Biol. 32: 557-563.

Song J and Hedgcoth C (1994). Influence of nuclear background on transcription of a chimeric gene (orf256) and coxI in fertile and cytoplasmic male sterile wheats. Genome 37: 203-209.

Vos P, Hogers R, Bleeker M, Reijans M, et al. (1995). AFLP: a new technique for DNA fingerprinting. Nucleic Acids Res. 23: $4407-4414$ 